\title{
A Strategic Marketing Plan
}

\section{The Context}

Throughout much of American history our universities were protected enclaves, respected well enough, but mostly unnoticed and allowed to go about their business unchallenged and largely unfettered. What a contrast today when the university finds itself defined as a key economic, political, social, and cultural institution as the result of extraordinary transformations occurring throughout our nation and the world. We are rapidly evolving into a new post-industrial society in which the key strategic resource necessary for prosperity and social well-being has become knowledge itself. Indeed, we are entering what might be called "an age of knowledge" in which educated people and their ideas play the role that in the past was played by natural resources or geographic location or labor pools. In the pluralistic, knowledge-intensive, global future that is our destiny it is clear that the quality of and access to education in general, higher education in particular, and the research university most specifically of all are rapidly becoming the key factors in determining the strength and prosperity of our state.

Harvard's Derek Bok notes that "In all advanced societies, our future depends to an ever-increasing extent on new discoveries, expert knowledge, and highly trained people. Like it or not, universities are our principal source of all three ingredients." This view is reinforced by Erich Bloch, former Director of the National Science Foundation, who notes, "The solution of virtually all the problems with which government is concerned: health, education, environment, energy, urban development, international relationships, space, economic competitiveness, and defense and national security depends upon creating new knowledge, and hence, upon the health of America's research universities."

Ironically enough, the increasingly critical role assigned to universities has not brought with it increased prestige, public confidence, or respect.

Instead, like so many other institutions in our society, we find ourselves roundly criticized from right, left, and center and even from within by many faculty, students, and staff for flaws large and small, fundamental and trivial. The American research university is clearly under attack: attacked by parents and students for the uncontrolled escalation of tuition, criticized by governors for financial irresponsibility, investigated by the Department of Justice for price fixing and tuition and financial aid, criticized by Washington and indeed our own faculties for rising indirect costs associated with research, attacked by Congress for alleged conflicts of interest, by legislators for the tenure system, and attacked by the left and the right for the quality of undergraduate education. 


\section{The Challenge}

The fundamental problem here is the degree to which the universities have allowed others to set the agenda, to determine the issues concerning higher education. The early antecedents to this shift in the public debate probably can be traced back to the efforts of William Bennett as Secretary of Education. Although Bennett was well-aware that the real challenge in American education was at the primary and secondary level ("A Nation at Risk" had appeared shortly before his tenure as Secretary began), he also recognized that dealing with problems facing K-12 education was a risky strategy since they appeared intractible. Hence, he decided to make his personal mark by launching a new offensive against a more vulnerable target, higher education, by accusing the universities of elitism and disregard for fundamental values, while characterizing their students as "spoiled". The attack on the values of the modern university was joined by intellectuals such as Allan Bloom's "The Closing of the American Mind".

The attacks launched against higher education in the ensuing years can be roughly classified into three areas:

i) Portrayal of universities as big, self-centered, and greedy: Included in this class of concerns are the rising costs of education--first launched by the media, but rapidly embraced by politicians, "price-fixing" charges leveled at private universities which were engaged in consultation on financial aid packages and tuition setting, and most recently, the charges of inappropriate use of federal research grants, most dramatically illustrated by Congressman John Dingell's hearings concerning Stanford University's use of federal dollars paid for overhead ("indirect cost") on research grants.

ii) The social climate on college campuses: The charges leveled at colleges concerning racism on the campuses--fueled by the growth of a new generation of student activists generating their power base from ethnic tensions; concerns about excessive alcohol and drug use (the raids on the fraternities at the University of Virginia being a recent case in point).

iii) The intellectual integrity of universities: Here, the charges include the faculty's preoccupation with "useless" research at the expense of teaching, the political correctness debate, and scientific fraud (the Utah cold fusion incident or the David Baltimore case). 
It is clear that as long as higher education allows others to determine and control the agenda, it will continue to find itself on the defensive, responding to first one negative issue and then another. This continued siege of the academy will continue to erode public confidence and trust in the American university, at just that moment in our history in which we become even more dependent on these institutions.

\section{A Proposal}

It is clear that higher education must take steps to regain control of the agenda, to begin to control the public debate, changing or reshaping context of the debate to achieve a more positive emphasis. Key will be a well-conceived campaign to turn people's attention to what higher education is really all about: educating the young people of our nation for the challenges ahead, doing the research that will determine our prosperity and quality of life, and providing the leadership necessary for our nation in a rapidly changing world.

The general structure of the effort can be represented by layered strategy as shown by the diagram below:

\section{$\underline{\text { Strategic Marketing Process }}$}

Process:

1) Develop the themes

...vision statement

...measureable objectives

2) Market research ...identify constituencies ...determine attitudes

3) Shape market (and objectives) ...Strategic plans at each level ...build networks ...use consultants as necessary

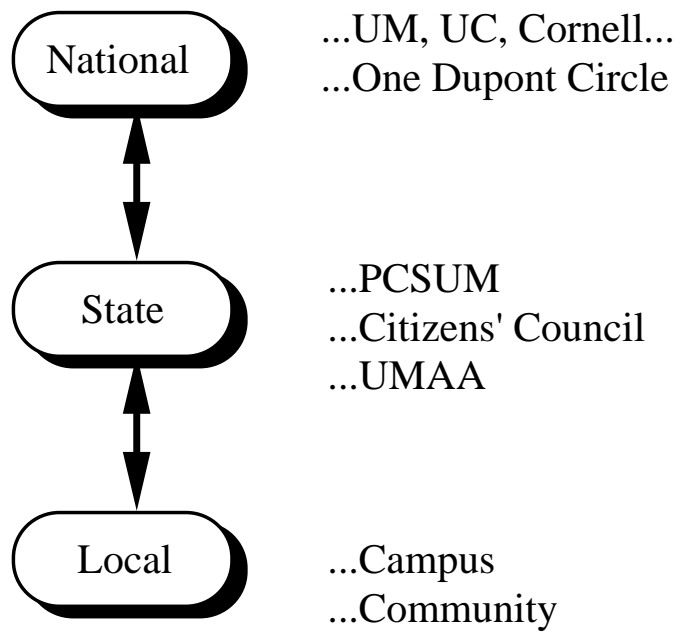

The "strategic marketing process" itself is a rather classical one, beginning with an effort to develop key themes and objectives, then determining both the nature and views of key constituencies, and finally attempting to better shape these 
views and align them with the objectives of higher education. Three levels of activity have been identified:

i) a national effort, dealing with the American public at large (and the national media),

ii) a broad outreach effort across the state of Michigan, dealing with public perception, the media, and well as with a more focused political agenda, and

iii) local efforts, aimed both at the various constituencies on campus (students, faculty, staff) and those in the surrounding community (Ann Arbor, Washtenaw Country, southeastern Michigan).

The basic approach at all three levels will be similar, but implemented by different groups:

i) To first take some highly visible action to respond to some of the criticisms and concerns--since they do contain some truth, and our public credibility requries demonstrating that we take criticism quite seriously. Here, however, we need to choose the battlefield quite carefully, responding only to a few of the more critical issues, and neutralizing others of less relevance or importance.

ii) At the same time, we need to launch a parallel effort to push several positive themes relativing to how the university is needed by our soceity in the 1990s and beyond. Examples might include: the education pipeline, economic competitiveness, and health care.

iii) We need to take steps to build more permanent structures or organizations capable to continuing this effort for the long term. For example, at the national level, it is clear that the One Dupont Circle associations (AAU, NASULGC, ACE) must be completely overhauled.

IV. Objectives for the 1990s

The first step in any such efforts will be the development of an appropriate "vision statement" for the University. For example, we might choose a theme such as leadership: 
Vision Statement: The University of Michigan seeks to provide the leadership for America and the world in determining the nature of the university of the 21st Century, through the unique combination of the quality, size, comprehensiveness, and innovation characterizing its educational, research, and service programs.

(Incidentally, if this seems a bit overly ambitious, it should also be recognized that a century ago the University of Michigan played a similar role in defining the character of the university for the 20th Century...) $n$ arriving at such a vision statement, we must keep foremost in mind the fundamental missions, purposes, and values of the university. There are a variety of forums and processes for this effort, including the Capital Campaign effort, the Futures Group, and so forth.

Next will be the articulation of some specific objectives for the 1990s. Here we should seek to develop these objectives in as precise and quantitative a form as possible, so we can measure our progress--or lack there of--quite clearly.

Examples of Possible Objectives for the 1990s:

1. To build private support to a level comparable to state support...thereby putting the University on a four-legged foundation of support (state appropriation, federal grants, tuition and fees, and private support). Stated in more quantitative terms, our objective would be to build the combination of annual gifts received and income on endowment to a level of $\$ 250$ million (1990 dollars) by the year 2000.

2. Michigan Mandate Objectives:

I: To achieve "proportionate representation" in students by 2000 ...i.e., according to 1990 Michigan census data, achieve at least $13.9 \%$ black, 2.2\% Hispanic, and $0.6 \%$ Native American representation. (In this regard, it should be noted that we are already well above target representations for all ethnic groups with the exception of African Americans.) Similar targets could be set for faculty and staff.

II: To build a truly multicultural learning community, resisting the forces of separatism and particularism, and instead developing mechanisms to unite people from different racial, ethnic, religious, and economic backgrounds. (This is a particularly difficult objective to quantify.)

3. To restructure the University by implementing total quality management methods to improve the quality and efficiency of operations. (We could develop a series of quantitative targets to measure this effort.) 
4. To dramatically improve the quality of the Board of Regents:

...by impoving the quality of individuals nominated and elected to the Board

...by educating the Board more effectively concerning their responsibilities to support the institution

...by broadening the selection process for Regents, e.g., by achieving a constitutional amendment to increase the size of the Board to 24 members, with 8 elected, 8 appointed by the Governor, and 8 selected by the UM Alumni Association

5. To move to a public/private hybrid university, similar to Cornell:

...with instate tuition $=50 \%$ outstate tuition $=50 \%$ private levels

...with a mixture of private and public schools adn colleges

...with the autonomy of a private university

6. To become the first truly "world" university in America

...moving from "state" --> "national" --> "world"

...enrollments: $50 \%$ instate...50\% outstate

$75 \%$ U.S. ...25\% international

There are many other quantitative objectives we might consider:

i) having all of our programs ranked in the top 10...e.g., USN\&WR...

ii) doubling the number of members of the National Academies on our faculty

iii) attracting (or developing) " $x$ " Nobel Laureates on our faculty

iv) becoming the leading public university in the number of citations of the publications of our faculty

v) becoming the nation's leading university in sponsored research volume (just as we now are in clinical volume or athletic attendance...)

V. Some Particular Strengths and Weaknesses

Strengths and Opportunities:

1. The University has extraordinary emotional reach through its quite unusual success in:

...Michigan athletics (particularly football)

...University Hospitals (which serve more

patients than any other academic medical center) 
...cultural activities (arguably the best in the nation)

...political activism (usually a bellweather for society)

2. The University of Michigan already is far down the road toward becoming a national public university. For example, it currently enrolls more out-ofstate students than either Stanford or Harvard! (30\% of 22,000 $=6,000$ outof-state undergraduates).

Weaknesses and Challenges:

1. Concerns have been raised that the University is rather short on broad vision within the ranks. Those few faculty who exhibit it tend to be pulled down by others (e.g., our efforts to "globalize the university" or to achieve a world-class information technology environment). This is coupled with the same populist "extraordinary intolerance of extreme excellence" that plagues many other midwestern universities.

2. The reality of the situation is that the most distinguished and comprehensive of the public research univresity are well down the road to becoming more "private-like", both in their financing and their operating philosopies. But is is difficult to portray a "public to private" transition strategy, since "private" has connotations of elitism and exclusiveness. Hence one of our challenges will be redefining the nature of the "public" university for the 21st Century. In particular, we must develop a strategy that will make the case that the University of Michigan's "publics" are broadening beyond the state and even federal level to the world itself.

3. There is no history of strong private support for higher education in Michigan. This is manifest in the absence of distinguished private universities in the state. The philanthropy of the auto rich went to the arts, to the Detroit Institute of Arts or the Detroit Symphony Orchestra, and not to education (perhaps because the auto barons were, themselves, essentially uneducated). Further, the presence of a strong tax base allowed the building of very high quality public institutions. 